\title{
Interlocking Nail Combined with Locking Plate Fixation for a Distal Diaphysis Femur Comminuted Fracture in a Dog
}

\author{
Maria Eduarda Bastos Andrade Moutinho da Conceição', Levi Oliveira dos Santos², \\ Guilherme Sembenelli', Carolina Gonçalves Dias Lima', Thiago André Salvitti de Sá Rocha', \\ Bruno Watanabe Minto' \& Luis Gustavo Gosuen Gonçalves Dias'
}

\begin{abstract}
Background: Interlocking Nail (ILN) is similar a solid intramedullary pins with screws or bolts passing through one and nail holes (locking effect). This implant mostly have been putted normograde, passing by trochanteric fossa of femur, although it is reported to be inserted through the knee, passing by fracture focus and ending close to proximal femur. It is carried out especially when there is a comminuted fracture in distal third shaft of femur. Locking plate systems work as internal fixators with some advantages compared to conventional plates. It can be used combined with intramedullary pin, and is an effective technique for increase stifeness stabilization of comminuted long-bone fractures, especially for bending. Some studies reported the use of plate-nail to increase even more the stiffness of implants, because of locking screw in plate and nail. Based on the same propose, we aim to report a case of an ILNs normograde (from distal to proximal) connected to a locking plate in highly comminuted distal diaphyseal fracture since it is rarely report in veterinary medicine orthopaedics. Case: A 5-year-old male mixed breed dog was assessed and diagnosed a fracture of the femur in the right pelvic limb. On physical examination, the dog had nonweight bearing lameness in the affected limb and, mobility of the fragments was noted following digital pressure. A comminuted fracture of the distal diaphysis of the femur was identified. A lateral approach to the shaft of the femur, the incision was extended to the stifle joint through a lateral incision because the fracture seemed to extend throughout the physis. Open but do not touch approach was performed and reduction was gotten without modified environment of fracture hematoma. A surgical drill was inserted through the access in distal extremity of the bone to open the medullary cavity of the femur. After that, an interlocking nail was inserted into the opening into the distal fragment, the fracture was reduced and the nail was inserted towards the proximal end of the bone. At the next stage the nail was fitted into the medullary canal and it was locked relative to the main fragments of the femur using locking head screws that were anchored in the load carrier of the plate. Postoperative radiographic views documented appropriate implants location and satisfactory femur fracture alignment. At 3 weeks, the patient showed functional use of the limb with partial weight bearing. Discussion: A biomechanical study comparing plate-rod and plate-nail system in gap fractures, showed that maximum load was significant different between the groups, and in plate-nail it was always heavier, it occurs because of the nail bigger diameter and screws pass through nail holes. What prove that this system is stiffer than plate-rod, so because this patient has osteopenia and thin cortical bone like showed previously, we preferred to use nail than intramedullary pin. The ILN could be introduced from proximal to distal femur (antegrade or normograde) and passing through the knee (called in medicine by retrograde, although in veterinary medicine this way is called normograte too), it depends on bone conformation. Several studies used normograde via in femur from distal to proximal, especially in distal fracture. In this case, it was used this via, by the knee, because it would promote better bone stock to insert the screws, since the nail was putted as close as possible from articular surface. In conclusion, the case reported here documented that the combination of a normograde (from distal to proximal) interlock nail with a locking plate provides a rigid fixation method, promoting satisfactory functional recovery time. Further investigations should be performed using plate-nail in vivo to give to us more precise data.
\end{abstract}

Keywords: biological osteosynthesis, canine, orthopaedics, retrograde nail. 


\section{INTRODUCTION}

Comminuted diaphyseal femur fractures occur commonly and remain challenging because of their high degree of instability [6,19]. Biological osteosynthesis aims to maintaining fracture haematoma and growth factors, promoting faster bone healing $[3,12,14]$. Although to allow callus formation, the implant is supposed to support all weight bearing and provide adequate stability [10].

Interlocking Nail (ILN) is similar a solid intramedullary pins with screws or bolts passing through one and nail holes (locking effect), it promote resistance in torsional, compressive, and bending forces [2,3]. This implant mostly have been putted antegrade, passing by trochanteric fossa of femur [8], although it is reported to be used retrograde in humans, inserted through the knee, passing by fracture focus and ending in proximal femur. It is need when there is a comminuted fracture in distal third shaft of femur $[1,5,11]$. However, this tip of insertion in veterinary medicine and in this paper is called normograde (distal to proximal).

Locking plate systems work as internal fixators with some advantages compared to conventional plates $[13,16]$. The locking mechanism between screw and plate-hole provides angular stability increasing the construct strength, and reduces implant to bone contact [13]. It can be used combined with intramedullary pin, and is an effective technique for increase stifeness stabilization of comminuted long-bone fractures, especially for bending. It occur because the pin is in neuter axis of bone [16].

Some studies reported the use of plate-nail to increase even more the stiffness of implants, because of locking screw in plate and nail $[9,10]$. Based on the same propose, we aim to report a case of an ILNs normograde (from distal to proximal femur) connected to a locking plate in highly comminuted distal diaphyseal fracture since it is rarely report in veterinary medicine orthopaedics.

\section{CASE}

A 5-year-old male mixed breed dog was presented to the surgery service of the FCAV - Unesp Jaboticabal after an automobile trauma. The patient was assessed and diagnosed a fracture of the femur in the right pelvic limb. On physical examination, the dog had nonweight bearing lameness in the affected limb and, mobility of the fragments was noted following digital pressure.
Mediolateral and craniocaudal radiographs of the femur were taken under general anesthesia. A comminuted fracture of the distal diaphysis of the femur was identified, furthermore it was observed osteopenia and a thin cortical bone (Figure $1 \mathrm{~A}$ ). After a complete physical and examination, was taken hemogram, creatinine and alanine aminotransferase (ALT). The patient was prepared for the surgery procedure in the day after. It was prescript for use at home tramadol $\left(\text { Tramal }^{\circledR}\right)^{1}[3 \mathrm{mg} / \mathrm{kg}]$, dipyrone $\left(\text { Lisador }^{\circledR}\right)^{2}$ [25 mg/ $\mathrm{kg}$ ] and cephalexin $\left(\text { Cefalexina }^{\circledR}\right)^{3}[30 \mathrm{mg} / \mathrm{kg}]$.

The patient was premedicated with morphine $\left(\text { Dimorf }^{\circledR}\right)^{4}[0.3 \mathrm{mg} / \mathrm{kg}$, intramuscularly $]$ and chlorpromazine $\left(\text { Clorpromaz }^{\circledR}\right)^{5}[0.2 \mathrm{mg} / \mathrm{kg}$, intramuscularly]. Cephazolin $\left(\mathrm{Kefazol}^{\circledR}\right)^{6}[30 \mathrm{mg} / \mathrm{kg}$, intravenously] was administered. Anesthesia was induced with propofol (Provive $\left.1 \%{ }^{\circledR}\right)^{7}[2-4 \mathrm{mg} / \mathrm{kg}, \mathrm{IV}]$, and maintained on isofluorane (Isoflurano $\left.{ }^{\circledR}\right)^{8}$ vaporized in $100 \%$ oxygen in a semi-closed circuit.

The dog was positioned in lateral recumbence under general anesthesia and the right pelvic limb aseptically prepared. After a lateral approach to the shaft of the femur, the incision was extended to the stifle joint through a lateral incision because the fracture seemed to extend throughout the physis. Open but do not touch approach was performed and reduction was gotten without modified environment of fracture hematoma (Figure 1 B). Because of the complex type of fracture, an interlocking nail combined with a locking plate was elected as the fixation method.

A surgical drill was inserted through the access in distal extremity of the bone to open the medullary cavity of the femur. After that, an interlocking nail was inserted into the opening into the distal fragment, the fracture was reduced and the nail was inserted towards the proximal end of the bone.

At the next stage the nail was fitted into the medullary canal and it was locked relative to the main fragments of the femur using locking head screws that were anchored in the load carrier of the plate. A guide was attached to the nail to ensure that the plate screws are correctly aligned with the nail's transverse openings and the locking plate was placed on the bone to assess whether further contouring is required.

Further bending of the plate was performed to provide the lateral condylar fracture repair using the same locking plate. Once the proper caudal curvature of the plate has been obtained, the plate was twisted to 
match the surface of the bone and the screws inserted (Figure $1 \mathrm{~B}$ and $\mathrm{C}$ ). At the last stage of the procedure the wounds were sutured using nylon.

Postoperative radiographic views documented appropriate implants location and satisfactory femur fracture alignment with restoration of normal length of the bone when compared with the radiographs of the contralateral limb. At 3 weeks, the patient showed functional use of the limb with partial weight bearing.

Follow-up radiographs five months postoperatively revealed satisfactory healing of the fracture. However, the orthopedic examination revealed mild lameness of the affected limb. Therefore, we elected for the removal of the plate, because it seemed to compromise the integrity of the ligaments and tendons of the stifle. In the day after, the plate and screws were explanted from the femur under general anesthesia. Follow-up examination 3 weeks after the last procedure revealed that the dog had regained full activity without any lameness. A x-ray at 45 days postop shown that bone was healed (Figure $1 \mathrm{D}$ and E).

\section{DISCUSSION}

Some studies $[9,10]$ showed that the plate-nail system as well as plate-rod, enable an alignment of the bone fragments without being necessary a precise anatomic reconstruction of the fracture fragments. When the plate is used as a single fixation method and the anatomic reconstruction and compression of the fracture fragments are not possible, it is more difficult to get ideal alignment and length of femur, because much of muscle involves this bone.

A biomechanical study comparing plate-rod and plate-nail system in gap fractures, showed that maximum load was significant different between the groups, and in plate-nail it was always heavier, it occurs because of the nail bigger diameter and screws pass through nail holes [9]. What prove that this system is stiffer than plate-rod, so because this patient has osteopenia and thin cortical bone like showed previously, we preferred to use nail than intramedullary pin.

Moreover, the use of mostly interlocking nail lonely allows a movement in fracture focus, called slack, because the holes in nail are broader than screw diameter, and it can result in delayed union or nonunion [3]. The use of plate combined with nail avoids this complication and make construction stiffer in torsion force.

To emphasize the importance of this choice, the approach was biological, what need all weigh be-

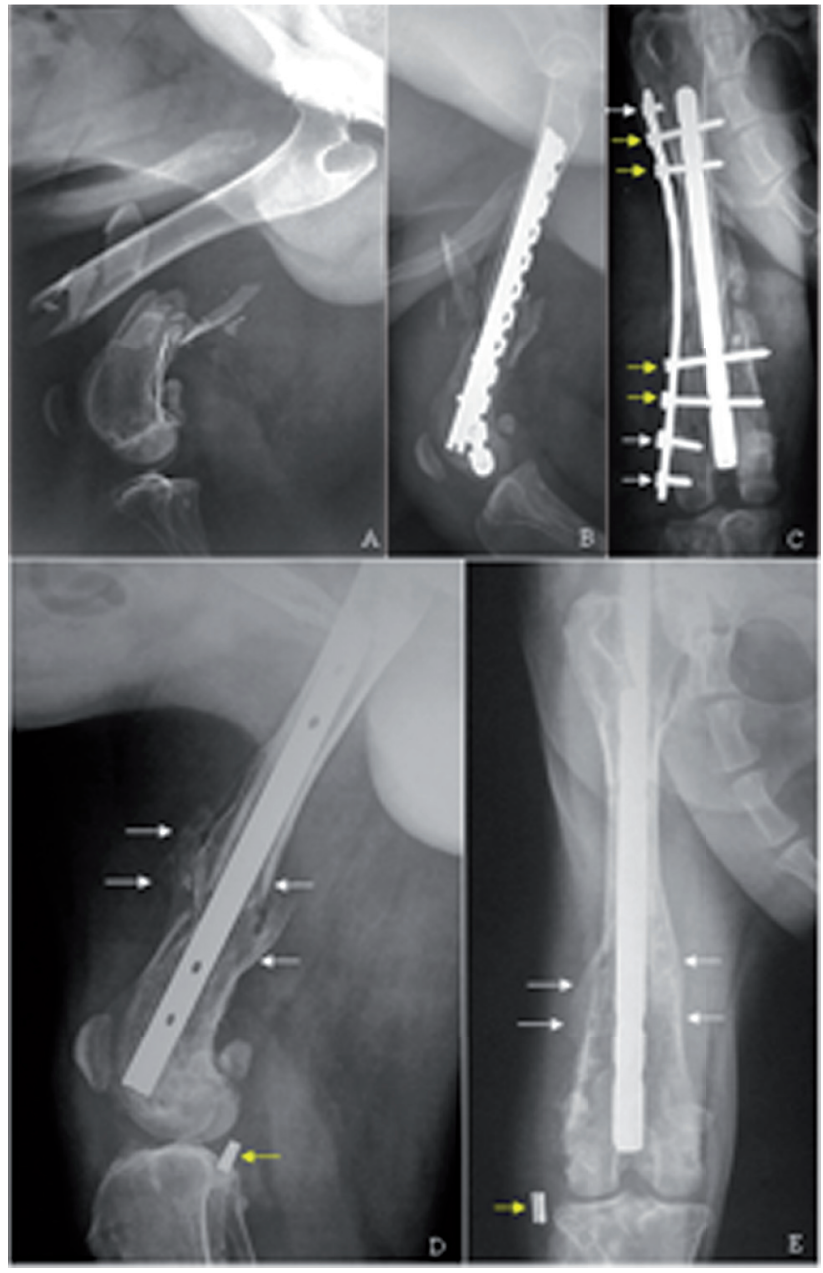

Figure 1. Radiographic images about pre and postoperatory of a male dog's right femur underwente to plate-nail ostheossinthesis with intramedullary nail isertede via normograde by the knee (distal to proximal) of $8 \mathrm{~mm}$, locked with reconstructive plate of $3.5 \mathrm{~mm}$. It was performed open but do not touch technique. A- Cominuted fracture of distal diaphysis of the femur, it can be seen thin cortical bone. B- Lateral view X-ray of immediate postoperative, it was obtained good alignment of fragments. C- These is bone healing at five months postoperative, four screws are locked in palte and nail (yellow arrows) and three screws are locked only in plate (white arrows). D- Lateral view, and cranial view of 45 days postoperative of second surgery, performed to take off some screws and cranial crutiate ligament treatment with extracapsular suture using clamps (yellow arrows). $\mathrm{E}$ - Anterior view showing bone remodeling (white arrows).

aring suport by the implants until bone healing [10]. Furthermore some complication involving the use of intramedullary pin associated to plate bone is pin migration, but using nail it couldn't occur because this implant is locked by screws [17].

The ILN could be introduced for two ways, from proximal to distal (antegrade) and normograde from distal from proximal (called in medicine by retrograde), it depends on bone conformation. Several studies used normograde through the knee femur, especially in distal fracture [5,20]. Some retrospective studies in human showed that use this technique, introducing nail by the knee, was well successes and had 
the same healing time and complications that antegrade via, and is usually in distal diaphyseal comminuted fractures. In this case, it was used this via because it would promote better bone stock to insert the screws, since the nail was putted as close as possible from articular surface of knee $[5,11,15]$.

Some of more reported complications in osteosyntesis are nonunion, malunion, delayed union, osteomyelitis, sarcoma, fatigue failure of the screw or plate, bending plate and pull out of screws, error of locking screw in nail $[4,7,18]$, none of this complications was observed in our patient. Moreover studies in humans report knee pain and arthrosis when the nail is putted through this joint $[1,15]$, like in our study, but we can't affirm if the osteoarthrosis observed was related with nail introduction or cruciate ligament disease.

In conclusion, the case reported here documented that the combination of a normograde (from distal to proximal) interlock nail with a locking plate provides a rigid fixation method, promoting satisfactory functional recovery time. Further investigations should be performed using plate-nail in vivo to give to us more precise data.

\section{MANUFACTURERS}

\author{
${ }^{1}$ Pharmacia Brasil. Guarulhos, SP, Brazil. \\ ${ }^{2}$ Cosmed Indústria de Comércio e Medicamentos SA. Barueri, SP, \\ Brazil. \\ ${ }^{3}$ LaboratórioTeuto. Anápolis, GO, Brazil. \\ ${ }^{4}$ Laboratório Cristália. Itapira, SP, Brazil. \\ ${ }^{5}$ União Química Farmacêutica Nacional S.A. Embú-Guaçu, SP, \\ Brazil. \\ ${ }^{6}$ Elli Lilly do Brasil Ltda. São Paulo, SP, Brazil. \\ ${ }^{7}$ Claris Produtos Farmaceuticos do Brasil. Barueri, SP, Brazil. \\ ${ }^{8}$ Instituto Bioquímico. Itatiaia, RJ, Brazil.
}

Declaration of interest. The authors report no conflicts of interest. The authors alone are responsible for the content and writing of the paper.

\section{REFERENCES}

1 Becher S. \& Ziran B. 2012. Retrograde intramedullary nailing of open femoral shaft fractures: A retrospective case series. The Journal of Trauma and Acute Care Surgery. 72(3): 696-698.

2 Bruckner M., Unger M. \& Spies M. 2016. Early Clinical Experience with a Newly Designed Interlocking Nail System - Targon VR Vet. Veterinary Surgery. 45: 754-763.

3 Déjardin L.M., Guiot L.P. \& von Pfeil D.J. 2012. Interlocking nails and minimally invasive osteosynthesis. Veterinary Clinic North America Small Animal Practice. 42(5): 935-962.

4 Duhautois B. 2003. Use of veterinary interlocking nails for diaphyseal fractures in 305 dogs and cats: 121 cases. Veterinary Surgery. 32(1): 8-20.

5 Gurkan V., Orhun H., Doganay M., Salioglu F., Ercan T., Dursun M. \& Bulbul M. 2009. Retrograde intramedullary interlocking nailing in fractures of the distal femur. Acta orthopaedica et traumatologica turcica. 43(3): 199-205.

6 Haaland P.J., Sjöström L., Devor M. \& Haug 2009. A. Appendicular fracture repair in dogs using the locking compression plate system: 47 cases. Veterinary and Comparative Orthopaedics and Traumatology. 4: 309-315.

7 Jackson L.C. \& Pacchiana P.D. 2004. Commom complications of fracture repair. Clinical Techniques in Small Animal Practice. 19(3): 168-179.

8 Johnson A.L. 2014. Fundamentos de Cirurgia Ortopédica e Tratamento de Fraturas e Tratamento de Fraturas Específicas. In Fossum T.W. (Ed). Cirurgia de Pequenos Animais. 4.ed. Rio de Janeiro: Elsevier, pp.1033-1212.

9 Mesquita L.R., Muzzi L.A.L., Lima J.T., Muzzi R.A.L., Lacreta Junior A.C.C. \& Silva W.G. 2015. Biomechanical Comparison of Plate-Nail Vs. Plate-Rod for experimentally-Induced Gap Fractures in ex vivo Canine Femora. Asian Journal of Animal Science. 9(6): 361-369.

10 Muzzi L.A.L., Muzzi R.A.L., Gianico A.T. \& Mesquita L.R. 2009. Association of interlocking-nail and bone plate (plate-nail) as a new method of fixation for long bones fractures in dogs. ClínicaVeterinária. 14(1): 244-245.

11 Papadokostakis G., Papakostidis C., Dimitriou R. \& Giannoudis P.V. 2005. The role and efficacy of retrograding nailing for the treatment of diaphyseal and distal femoral fractures: a systematic review of the literature. Injury. 36: 813-822.

12 Patil D.B., Adamiak Z. \& Piórek A. 2008. Veterinary interlocking nailing and its augmentation for fracture repair. Polonium Journal of Veterinary Science. 11: 187-191.

13 Perren S.M. 2002. Evolution of the internal fixation of long bone fractures. The scientific basis of biological internal fixation: choosing a new balance between stability and biology. Journal of Bone and Joint Surgery. 84: 1093-1110. 
14 Piórek A., Adamiak Z., Matyjasik H. \& Zhalniarovich Y. 2012. Stabilisation of fractures with the use of veterinary interlocking nails. Pakistan Veterinary Journal. 32: 10-14.

15 Ricci W.M., Bellabarba C., Evanoff B., Herscovici D., Di Pasquale T. \& Sanders R. 2001. Retrograde versus antegrade nailing of femoral shaft fractures. Journal of Orthopaedic Trauma. 15(3): 161-169.

16 Schwandt C.S. \& Montavon P.M. 2005. Locking compression plate fixation of radial and tibial fractures in a young dog. Veterinary and Comparative Orthopaedics and Traumatology. 18: 194-198.

17 Stifler K.S. 2004. Internal fracture fixation. Clinical Techniques in Small Animal Practice. 19(3): 105-113.

18 Vallefuoco R., Le Pommellet H., Savin A., Decambron A., Manasero M., Vlateau V., Gauthier O. \& Fayolle P. 2016. Complications of appendicular fracture repair in cats and small dogs using locking compression plates. Veterinary and Comparative Orthopaedics and Traumatology. 1: 46-52.

19 Von Pfeil D.J., Déjardin L.M., Decamp C.E., Meyer E.G., Lansdowne J.L., Weerts R.J.H. \& Haut R.C. 2005. In vitro biomechanical comparison of a plate-rod combinationconstruct and an interlocking nail-construct for experimentally induced gap fractures in canine tibiae. American Journal of Veterinary Research. 66(9): 1536-1543.

20 Zirkle L.G. \& Shearer D. 2009. Technique for retrograde and antegrade approaches to femur. Techniques in Orthopaedics. 24(4): 247-252. 